\title{
Editorial: The importance of being collagen
}

The eye, by its specialized structure and accessibility to examination, provides a unique window for the study of connective tissues when they are involved in systemic disease processes. The severest forms of ocular complications-for example, keratolysis and necrotizing scleritis-underline the vital role which collagen plays in the basic architecture of the eye and emphasize the importance of the study of control mechanisms for its biosynthesis and biodegradation, and their perturbation by pathological processes.

At present the process of extracellular fibre formation is the subject of active investigation. Recent studies (Olsen and Prockop, 1974) have demonstrated the mobilization of previously synthesized procollagen within Golgi vesicles which are then transported to the plasma membrane by the microtubular system. After fusion of the Golgi vesicle with the plasma membrane the procollagen molecules are released into the extracellular space where the non-helical polypeptide extensions are cleaved by a procollagen peptidase. This allows normal fibre bundle formation and cross linking of the molecules to occur (Lapière and Pierard, 1974). Deficient activity of this enzyme is responsible for dermatosparaxis in the calf. In this hereditary disorder of connective tissue, procollagen forms the fibrous framework (Tenaers, Ansay, Nusgens, and Lapière, 197I), and the dermal connective tissue is very fragile (Hanset and Ansay, 1967). Collagen synthesis can also be influenced by the extracellular matrix itself (Nevo and Dorfman, I972), and this control may be sufficiently sensitive to order the type of collagen synthesized (Slavkin, Croissant, and Guenther, 1975). In developing tissues the distribution patterns of collagen fibre width play an important role in morphogenesis (Robert and Robert, 1975), and in the embryonic eye, physical factors-such as, developing intraocular pressuremay operate to produce the highly structured orthogonal lattice of collagen fibres in the cornea, and so produce a regular conformational response.

The control of collagen biodegradation in vivo is less well understood at present, because of the many factors which seem to be involved. Circulating inhibitors of collagenase activity have been reported in serum, an $\alpha_{2}$ macroglobulin and $\alpha_{1}$ antitrypsin (Eisen, Bloch, and Sakai, 1970), and an $\alpha_{2}$ macroglobulin-enzyme complex in synovial fluids from patients with rheumatoid arthritis (Abe and Nagai, 1973). Dissociation of this complex in sodium thiocyanate (NaCNS) results in the 'unmasking' of considerable collagenolytic activity. These circulating inhibitors would therefore seem to be part of the homoeostatic control mechanism to prevent excessive collagenase activity in chronic inflammatory states. In addition, inactive enzyme precursors or procollagenases have been found in the culture media of bone explants in vitro (although the possibility that this is an inactive enzymeinhibitor complex has not been entirely excluded). In these experiments 'unmasking' of the latent collagenase activity was achieved after incubation with a variety of enzymic substances - for example, trypsin, lysosomal extracts, cathepsin BI, Kallikrein, and plasmin (Vaes and Eeckhout, 1975). Many of these substances could well be expected to operate in an inflammatory lesion, although these authors feel that other proactivators may further complicate the system. Collagenase activity may also respond to different controls in various organs. The collagenase production of involuting uterine explants has been shown to be markedly inhibited by progesterone, especially when augmented by dibutyryl cyclic adenosine monophosphate (AMP). Similar inhibitory effects of the cyclic nucleotide and theophylline (a cyclic phosphodiesterase inhibitor) were also found in human skin cultures but progesterone was inactive in this system (Jeffery, Koob, and Eisen, 1975); the same workers also showed that the skin collagenase production was inhibited by extremely low levels of cortisol and dexamethasone which were similarly effective on rheumatoid synovia. The recent demonstration of collagenase activity associated with corneal fibroblasts (Hook, Hook, and Brown, 1973) is obviously of particular interest. When the control mechanisms for this enzyme have been fully studied, the pathogenesis of a suddenly developing keratolysis or scleromalacia perforans will undoubtedly be better understood, and it is not too much to hope that collagenase inhibitors other than corticosteroids will be found, and will prove to be effective in the control of such connective-tissue destruction without concomitantly slowing down the rate of reparative synthesis.

Finally, one must consider how the foregoing outline of the underlying 'mechanics' can be modified by substances derived from the pathological lesions themselves. In this respect the granulomatous lesions of the sclera are of prime importance, as by definition they represent a failure of biodegradation and characteristically 
are a source of numerous acid hydrolases. In this connexion, ingested inert particles by rabbit synovial fibroblasts have been shown to secrete increased quantities of a collagenase (Werb and Burleigh, 1974) and a neutral proteinase (Werb and Reynolds, 1974). Neutral proteinases are of special importance by their action upon proteoglycan core protein, the dissolution of which enables further enzyme access. The ingestion of antigen/ antibody complexes by cells have also been shown to result in the extracellular release of lysosomal hydrolases (Henson, 1971; Weissman, Zurier, Spieler, and Goldstein, 197I). There are thus many other possibilities for collagenase production and/or activation from products secreted by cells involved in the granuloma.

The interrelations between immunopathological stimuli, connective-tissue enzymology and homoeostasis, in the ocular complications of rheumatoid arthritis and other connective-tissue diseases, will undoubtedly provide a very exciting field of ophthalmological investigation in the future.

\section{References}

ABE, S., and NAGAI, y. (1973) F. Biochem. (Tokyo), 73, 897

EISEN, A. Z., BLOCH, K. J., and SAKAI, T. (1970) F. Lab. clin. Med., 75, 258

haNSET, R., and ANSAY, M. (1967) Ann. Méd. vét., 7, 451

HENSON, P. M. (1971) F. exp. Med., 134, 114S

HOOK, R. M., нООк, C. W., and BROWN, S. I. (1973) Invest. Ophthal., 12, 77 I

JEFFERY, J. J., коов, T. J., and eISEN, A. z. (1975) In 'Dynamics of Connective Tissue Macromolecules', eds P. M. C.

Burleigh and A. R. Poole, p. 147. Elsevier North-Holland Excerpta Medica, Amsterdam

LAPIÈRE, CH. M., and PIERARD, G. (1974) J. invest. Derm., 62, 582

Nevo, Z., and Dorfman, A. (1972) Proc. nat. Acad. Sci. (Wash.), 69, 2069

OLSEN, B. R., and PROCKOP, D. J. (1974) Ibid., 71, 2033

ROBERT, B., and ROBERT, L. (I975) Protides Biol. Fluids, 22, 15

SLAVkin, H. C., CROISSANT, R. D., and GUENTHER, H. (1975) Ibid., 22, 23

TENAERS, A., ANSAY, M., NUSGENS, B., and LAPIERE, CH. M. (1971) Europ. Э. Biochem., 23, 533

vaEs, G., and EeckHout, Y. (I975) In 'Dynamics of Connective Tissue Macromolecules', eds P. M. C. Burleigh, and A. R. Poole, p. 129. Elsevier North-Holland Excerpta Medica, Amsterdam

WEISSMAN, G., ZURIER, R. B., SPIELER, P. J., and gOLDSTEIN, I. M. (197I) F. exp. Med., I34, I49S

WERB, Z., and BURLEIGH, P. M. C. (1974) Biochem. $\mathcal{F}$., 137, 373

, and REYNOLDS, J. J. (1974) F. exp. Med., 140, 1482 